Case Report

\title{
Psychopathology Related to Energy Drinks: A Psychosis Case Report
}

\author{
Daniel Hernandez-Huerta, ${ }^{1}$ Maria Martin-Larregola, ${ }^{2}$ Jorge Gomez-Arnau, ${ }^{2}$ \\ Javier Correas-Lauffer, ${ }^{2,3}$ and Helen Dolengevich-Segal ${ }^{2,3}$ \\ ${ }^{1}$ Department of Psychiatry, Ramon y Cajal University Hospital, Madrid, Spain \\ ${ }^{2}$ Department of Psychiatry, Henares University Hospital, Coslada, Madrid, Spain \\ ${ }^{3}$ Francisco de Vitoria University, Madrid, Spain \\ Correspondence should be addressed to Daniel Hernandez-Huerta; daniel.hernandez@salud.madrid.org
}

Received 3 November 2016; Accepted 18 December 2016; Published 2 January 2017

Academic Editor: Philipp Sand

Copyright (C) 2017 Daniel Hernandez-Huerta et al. This is an open access article distributed under the Creative Commons Attribution License, which permits unrestricted use, distribution, and reproduction in any medium, provided the original work is properly cited.

\begin{abstract}
Energy drinks (ED) are nonalcoholic beverages that have caffeine as their most common active substance. The rapid expansion of ED consumption has created concern in the scientific community as well as in the public opinion. We report a psychotic episode probably triggered by ED abuse in a young adult without previous psychotic disorders. We have reviewed the literature regarding the relationship between caffeine, energy drinks, and psychopathology. Few articles have been published about mental health effects of energy drinks and caffeine abuse. Nevertheless, this relationship has been suggested, specifically with anxiety disorders, manic episodes, suicide attempts, psychotic decompensation, and substance use disorder. ED consumption could represent a global public health problem because of the potential severe adverse effects in mental and physical health. To our knowledge, this article is probably the first case of psychosis related to ED abuse in an individual without previous psychotic disorders.
\end{abstract}

\section{Introduction}

ED constitute a relatively new product category in the wide soft drink market. The category includes a variety of nonalcoholic beverages marketed for their perceived effects as stimulants, energizers, and performance enhancers. The most common substance in ED is caffeine, which is often combined with taurine, D-glucurono-y-lactone, guaraná, maltodextrin, ginseng, carnitine, creatine, and gingko biloba; other common ingredients are vitamins and artificial and natural sweeteners [1]. Hundreds of different brands are now marketed with significant variation in their caffeine content (ranging from a modest $50 \mathrm{mg}$ to an alarming $505 \mathrm{mg}$ per can or bottle) and caffeine concentration (ranging from $2.5 \mathrm{mg}$ to $17.1 \mathrm{mg}$ per fluid ounce). The acute and long-term effects resulting from excessive and chronic consumption of ED are not yet fully known $[2,3]$.

The rapid expansion of ED consumption has created concern in the scientific community as well as in the public opinion. Available information suggests that ED consumption is becoming more and more widespread among young individuals, especially in relation to entertainment and sports practice. In the European Union, the highest prevalence of consumption was observed in the adolescent age group, with 68\% having consumed at least once in 2012. However, prevalence of consumption in adults was $30 \%$ and in children was $18 \%[4,5]$.

Caffeine seems to be the main ED compound to produce a stimulant effect $[6,7]$. Caffeine can influence the activity of neuronal control pathways in the peripheral and central nervous system (CNS). The neuropsychiatric effects of caffeine are mediated by antagonism of adenosine $A_{1}$ and $A_{2 A}$ receptors in the CNS. As adenosine inhibits dopaminergic neurotransmission, blockage of $\mathrm{A}_{2 \mathrm{~A}}$ receptors by caffeine may increase dopaminergic activity. Antagonism of $\mathrm{A}_{1}$ receptors regulates the release of neurotransmitters such as glutamate or acetylcholine. Caffeine differs from classical substances of misuse in causing dopamine release in the prefrontal cortex rather than the nucleus accumbens [8]. 


\section{Clinical Case}

The patient was an 18-year-old Spanish male with no relevant medical or psychiatric history. Regarding his substance use, he admitted daily use of tobacco (20 cigarettes/day, meeting criteria for tobacco use disorder), daily use of cannabis (3 cannabis cigarettes/day, meeting criteria for cannabis use disorder), and occasionally weekend drinking (no meeting criteria for alcohol use disorder). He denied consumption of other psychoactive substances. As for his family background there was a paternal uncle with an unspecified chronic mental illness.

He was admitted to a psychiatry ward after presenting with an acute psychotic episode. The clinical picture included delusions of reference and persecution, pressured speech, increased alertness, fright, suspiciousness, marked anxiety, and psychomotor agitation during previous days. Hallucinations were not identified. He was aware and oriented in person, place, and time. Over the previous week, he had felt very nervous due to the proximity of high school exams. Thus, he had been drinking about 6 ED cans $(80 \mathrm{mg}$ caffeine per can) per day during the last seven days. Also, he had been sleeping less than three hours per night in this period, until finally he showed global insomnia during the day prior to hospital admission. He denied increasing cannabis smoking in these days or consumption of other substances.

During his first day in the inpatient unit he presented severe acute psychomotor agitation that required mechanical restraint and high doses of medication (first olanzapine $20 \mathrm{mg}$ oral, followed by haloperidol $5 \mathrm{mg}$ and levomepromazine $25 \mathrm{mg}$ intramuscularly). After these treatments he exhibited low awareness and the ECG showed sinus bradycardia and QTc prolongation. He stayed 24 hours in the intensive care unit until his ECG was normalized and he recovered good awareness level. Urinary drug screening test was positive for cannabinoids and negative for opioids, benzodiazepines, cocaine, amphetamines, tricyclic antidepressants, and barbiturates. Additional tests (cranial CT and blood tests) were normal.

The patient returned to the psychiatry ward and was treated with olanzapine $10 \mathrm{mg}$ daily and there was cessation of caffeinated drinks. After three days, psychotic symptomatology had disappeared and he was discharged with diagnosis of Substance-Induced Psychotic Disorder (according to DSM-5 classification) relative to stimulants (ED) and cannabis. He was followed up at a mental health outpatient setting with positive global evolution. He remained abstinent to cannabis and ED. Antipsychotic treatment was gradually reduced and he was finally discharged of mental health service without pharmacological treatment two years later.

\section{Discussion}

Five caffeine-related syndromes are recognized in the Diagnostic and Statistical Manual of Mental Disorders, Fifth Edition (DSM-5) [9]; however, the International Classification of Diseases Tenth Revision (ICD-10) is less specific and only recognizes "mental and behavioural disorders due to use of other stimulants, including caffeine" [8] (Table 1).
TABLE 1: Caffeine-related syndromes in DSM-5 and ICD-10.

\begin{tabular}{ll}
\hline DSM-5 & ICD-10 \\
\hline (1) Caffeine-induced sleep disorder (F15.182, & \\
F15.282, F15.982) & (1) Mental and \\
(2) Caffeine-induced anxiety disorder & $\begin{array}{l}\text { behavioural disorders } \\
\text { due to use of other }\end{array}$ \\
(F15.180, F15.280, F15.980) & stimulants, including \\
(3) Caffeine intoxication (F15.929) & caffeine (F15) \\
(4) Caffeine withdrawal (F15.93) & \\
(5) Unspecified caffeine-related disorder & \\
(F15.99) & \\
\hline
\end{tabular}

Caffeine intake has been linked as a potential risk factor for a wide range of psychiatric and substance use disorders. A genetic factor seems to predispose people to both caffeine intake and the risk for psychiatric disorders [10]. For example, it has been described that individuals with the 1976T/T genotypes for A2A adenosine receptors showed higher levels of anxiety after caffeine administration than other genotypic groups $[11,12]$.

Some studies have demonstrated that the intake of large amounts of caffeine is associated with psychotic and manic symptoms and/or exacerbation of previous psychotic symptoms [13]. Case reports have also suggested that excessive caffeine intake may hamper the recovery of patients with bipolar disorder or manic-type mood episodes. For this reason, several guidelines recommend discontinuation of caffeine intake as one of the first steps in the treatment of mania [7].

Case report evidence suggests that caffeine might induce psychotic symptoms also in some individuals without previous psychotic disorders, but this has not yet been confirmed. This may result from an exacerbation of underlying paranoid traits. Also, reduction of caffeine intake has been associated with symptom improvement in patients with psychotic disorders [7]. Individuals with a predisposition to psychosis may have a greater disposition or demonstrate a lower threshold to develop psychopathology following ingestion of caffeine [14].

Recently, case reports of psychopathology related to ED consumption have been reported (Table 2).

Initial evidence to suggest that ED use can be associated with the occurrence/reoccurrence of psychiatric symptoms comes from these case reports. Although these cases imply that excessive consumption of energy drinks may act as a trigger for relapse in certain vulnerable people with preexisting mental health problems, cases have also emerged in which serious psychiatric symptoms have occurred in otherwise healthy individuals [15].

In a recent study, Marmorstein [16] examined the association between ED and coffee consumption and psychopathology among early teenagers. The author studied symptoms of depression, anxiety, conduct disorder (CD), and attention deficit hyperactivity disorder (ADHD) and found that ED and coffee consumption were concurrently associated with similar psychopathology symptoms. However, longitudinally, the associations between these beverages and psychopathology differed. Specifically, ED consumption at the initial 
TABLE 2: Case reports published about psychopathology related to ED consumption.

\begin{tabular}{|c|c|c|c|c|}
\hline Reference & Previous mental illness & ED consumption & $\begin{array}{l}\text { Psychopathology } \\
\text { related to ED } \\
\text { consumption } \\
\end{array}$ & Treatment \\
\hline Cruzado et al. [34] & No & $\begin{array}{l}4 \text { cans of Magnus }{ }^{\circledR} \text { Omnilife } \\
\text { Products }+5 \text { coffee cups, daily, } \\
\text { during several weeks }\end{array}$ & Manic episode & $\begin{array}{l}\text { Risperidone } \\
3 \mathrm{mg} / \text { day and ED } \\
\text { cessation }\end{array}$ \\
\hline Szpak and Allen [35] & No & $\begin{array}{l}7 \text { cans of unspecified ED } \\
\text { during two days }\end{array}$ & Suicide attempt & ED cessation \\
\hline \multirow{3}{*}{ Rizkallah et al. [36] } & $\begin{array}{l}\text { Case 1: bipolar disorder type I and } \\
\text { cocaine dependence }\end{array}$ & $\begin{array}{l}6 \text { cans of unspecified ED, } \\
\text { daily, during one week }\end{array}$ & Manic episode & ED cessation \\
\hline & $\begin{array}{l}\text { Case 2: bipolar disorder type II and } \\
\text { cocaine dependence }\end{array}$ & $\begin{array}{l}8 \text { cans of unspecified ED, } \\
\text { daily, during one month }\end{array}$ & Manic episode & ED cessation \\
\hline & $\begin{array}{l}\text { Case 3: bipolar disorder type I, } \\
\text { cannabis dependence, and cocaine } \\
\text { abuse }\end{array}$ & $\begin{array}{l}9 \text { cans of unspecified ED, } \\
\text { daily, during two weeks }\end{array}$ & $\begin{array}{c}\text { Mood } \\
\text { decompensation }\end{array}$ & ED cessation \\
\hline Cerimele et al. [37] & Schizophrenia & $\begin{array}{l}10 \text { cans of unspecified ED, } \\
\text { daily, during two months }\end{array}$ & $\begin{array}{c}\text { Psychotic } \\
\text { decompensation }\end{array}$ & ED cessation \\
\hline Berigan [38] & No & $\begin{array}{l}6-8 \text { cans of unspecified ED, } \\
\text { daily, during four months }\end{array}$ & Anxiety disorder & ED cessation \\
\hline \multirow{3}{*}{ Chelben et al. [39] } & $\begin{array}{l}\text { Case 1: cluster B personality } \\
\text { disorder }\end{array}$ & $\begin{array}{l}5 \text { cans of unspecified ED, } \\
\text { daily, during } 1 \text { week }\end{array}$ & $\begin{array}{c}\text { Mood } \\
\text { decompensation }\end{array}$ & ED cessation \\
\hline & $\begin{array}{l}\text { Case 2: bipolar disorder, borderline } \\
\text { personality disorder, and multiple } \\
\text { substance abuse }\end{array}$ & $\begin{array}{l}\text { 5-10 cans of unspecified ED, } \\
\text { daily, during one month }\end{array}$ & $\begin{array}{c}\text { Mood } \\
\text { decompensation }\end{array}$ & ED cessation \\
\hline & Case 3: schizophrenia & $\begin{array}{l}\text { 8-9 cans of unspecified ED, } \\
\text { daily, during one month }\end{array}$ & $\begin{array}{c}\text { Mood } \\
\text { decompensation }\end{array}$ & ED cessation \\
\hline Machado-Vieira et al. [40] & Bipolar disorder type I & $\begin{array}{l}6 \text { cans of Red Bull }{ }^{\circledR} \text { in total } \\
\text { during } 1 \text { week }\end{array}$ & Manic episode & ED cessation \\
\hline Menkes [41] & Schizophrenia & $\begin{array}{l}5 \text { cans of Demon Shot }{ }^{\circledR} \text { in } \\
\text { total during } 1 \text { week }\end{array}$ & $\begin{array}{c}\text { Psychotic } \\
\text { decompensation }\end{array}$ & ED cessation \\
\hline Sharma [42] & No & $\begin{array}{l}6-8 \text { cans of Red Bull }(550 \mathrm{~mL}) \\
\text { during } 1 \text { week }\end{array}$ & Manic episode & $\begin{array}{l}\text { Olanzapine } \\
10 \text { mg/day and ED } \\
\text { cessation }\end{array}$ \\
\hline
\end{tabular}

assessment predicted increases in $\mathrm{CD}$ and $\mathrm{ADHD}$ rates. Conversely, initial levels of ADHD hyperactivity symptoms predicted later increases in coffee consumption, while social anxiety was protective against increases in energy drink consumption [16].

Richards and Smith [15] have recently reviewed the literature about the chronic effects of ED on mental health. They concluded that although acute mood effects associated with ED appear often to be positive, chronic use also tends to be associated with undesirable mental health effects such as stress, anxiety, and depression. However, as almost all identified studies were cross-sectional and some did not control for other relevant factors such as sex, socioeconomic status, and additional caffeine intake, the nature of this relationship is not yet fully understood [15].

In this case report we hypothesize that psychotic symptoms could be related to the excessive consumption of ED during the days prior to hospitalization. Review of the topic shows similar case reports although there is not enough literature yet about the psychiatric effects of ED. Otherwise, we have to take into account other important factors that could play an important role in this case. These relevant factors are cannabis use disorder and sleep deprivation. Both have been linked with psychosis in several researches and, therefore, they have been able to contribute as etiologic and pathogenic factors.

Current cannabis abuse or dependence increases the risk of transition into psychosis in persons at ultrahigh risk of psychosis $[17,18]$. There have been few studies addressing the effects of caffeine and cannabis in combination, but they have been focused on their combined effects on memory but not in psychosis [19]. Our patient met criteria for cannabis use disorder and is important to take it into account in this psychotic process. However, psychotic symptoms only appeared after the excessive consumption of ED and, thus, cannabis could not be considered as unique etiologic factor.

Excessive intake of caffeinated ED leads to sleep deprivation [20], which also has implications for psychotic pathogenesis. Sleep deprivation has been associated with an increase in self-reported psychiatric symptoms, including somatic complaints, anxiety, depression, mania, and paranoia [21]. Insomnia symptoms have also been related to higher levels 
of persecutory thoughts, even in the general population [22]. Recently, another study has shown that sleep deprivation induces sensorimotor gating deficits and elevated selfreported psychosis-like experiences in healthy humans [23]. In our case report, sleep deprivation is probably consequence of excessive consumption of ED and excessive tension due to exam stress. This effect, in accordance with the other relevant factors, has been able to influence the emergence of psychotic symptoms.

It is also remarkable that the patient suffered a severe cardiovascular complication (sinus bradycardia and QTc prolongation) after antipsychotic drug administration. A possible QTc prolongation secondary to antipsychotic drugs is well-known $[24,25]$. However, cardiovascular effects, such as supraventricular tachycardia, long QT syndrome, or myocardial infarction, have also been described after ED intake [26-29]. In addition, a number of investigations have focused on the hemodynamic effects and endothelial functions of the consumption of energy drinks [30-33]. For this reason we hypothesize that the complication described in our patient could be multifactorial and not only related to antipsychotic drugs.

\section{Conclusions}

To our knowledge this case report is probably the first case of psychosis related to ED abuse in a patient without a previous diagnosis of psychotic disorder. ED abuse likely played the most important role in the pathogenesis of psychosis in this case report; however, other factors, such as cannabis use disorder, genetic factors, and sleep deprivation, were probably relevant and facilitated the process.

ED consumption could represent a global public health problem because of its potential severe adverse events. Few articles have been published on this important matter. The general public and potentially vulnerable users, such as adolescents, should be advised that caution is warranted when using these drinks, especially in large quantities over short periods of time or mixed with cannabis, alcohol, or other substances. More research is needed to determine the potential health and mental effects associated with ED consumption.

\section{Competing Interests}

The authors declare that there are no competing interests regarding the publication of this paper.

\section{Authors' Contributions}

Daniel Hernandez-Huerta conducted literature review and conceptualized and wrote the initial draft of the paper. Maria Martin-Larregola conducted literature review. Helen Dolengevich-Segal evaluated, treated, and obtained verbal informed consent of the patient. The authors Jorge Gomez-Arnau and Javier Correas-Lauffer provided substantive expertise to the conceptualization, writing, and editing of the paper. All authors contributed to and have approved the final paper.

\section{References}

[1] M. Martin Larregola and H. Dolengevich Segal, "Energy drinks o bebidas energéticas," in Nuevas drogas psicoactivas, $\mathrm{H}$. Dolengevich Segal, Ed., pp. 419-431, Grupo Editorial Entheos, Madrid, Spain, 2015.

[2] C. J. Reissig, E. C. Strain, and R. R. Griffiths, "Caffeinated energy drinks-a growing problem," Drug and Alcohol Dependence, vol. 99, no. 1-3, pp. 1-10, 2009.

[3] J. P. Higgins, T. D. Tuttle, and C. L. Higgins, "Energy beverages: content and safety," Mayo Clinic Proceedings, vol. 85, no. 11, pp. 1033-1041, 2010

[4] S. Zucconi, C. Volpato, F. Adinolfi et al., "Gathering consumption data on specific consumer groups of energy drinks," Supporting Publication, vol. 10, no. 3, pp. 1-190, 2013.

[5] D. Jackson, B. Cotter, R. Merchant et al., "433 getting HYPED! behavioral and physiological side-effects associated with energy drink and caffeine use among emergency department patients," Annals of Emergency Medicine, vol. 58, no. 4, pp. S324-S325, 2011.

[6] A. M. Arria, K. M. Caldeira, S. J. Kasperski et al., "Increased alcohol consumption, nonmedical prescription drug use, and illicit drug use are associated with energy drink consumption among college students," Journal of Addiction Medicine, vol. 4, no. 2, pp. 74-80, 2010.

[7] D. R. Lara, "Caffeine, mental health, and psychiatric disorders," Journal of Alzheimer's Disease, vol. 20, no. 1, pp. 239-248, 2010.

[8] A. P. Winston, E. Hardwick, and N. Jaberi, "Neuropsychiatric effects of caffeine," Advances in Psychiatric Treatment, vol. 11, no. 6, pp. 432-439, 2005.

[9] American Psychiatric Association, Diagnostic and Statistical Manual of Mental Disorders, American Psychiatric Association, Arlington, Va, USA, 5th edition, 2013.

[10] K. S. Kendler, J. Myers, and C. O. Gardner, "Caffeine intake, toxicity and dependence and lifetime risk for psychiatric and substance use disorders: an epidemiologic and co-twin control analysis," Psychological Medicine, vol. 36, no. 12, pp. 1717-1725, 2006.

[11] K. Alsene, J. Deckert, P. Sand, and H. de Wit, "Association between A2a receptor gene polymorphisms and caffeineinduced anxiety," Neuropsychopharmacology, vol. 28, no. 9, pp. 1694-1702, 2003.

[12] E. Childs, C. Hohoff, J. Deckert, K. Xu, J. Badner, and H. De Wit, "Association between ADORA2A and DRD2 polymorphisms and caffeine-induced anxiety," Neuropsychopharmacology, vol. 33, no. 12, pp. 2791-2800, 2008.

[13] A. Caykoylu, O. Ekinci, and M. Kuloglu, "Improvement from treatment-resistant schizoaffective disorder, manic type after stopping heavy caffeine intake: a case report," Progress in NeuroPsychopharmacology and Biological Psychiatry, vol. 32, no. 5, pp. 1349-1350, 2008.

[14] D. W. Hedges, F. L. Woon, and S. P. Hoopes, "Caffeine-induced psychosis," CNS Spectrums, vol. 14, no. 3, pp. 127-131, 2009.

[15] G. Richards and A. P. Smith, "A review of energy drinks and mental health, with a focus on stress, anxiety, and depression," Journal of Caffeine Research, vol. 6, no. 2, pp. 49-63, 2016.

[16] N. R. Marmorstein, "Energy drink and coffee consumption and psychopathology symptoms among early adolescents: crosssectional and longitudinal associations," Journal of Caffeine Research, vol. 6, no. 2, pp. 64-72, 2016. 
[17] C. Ksir and C. L. Hart, "Cannabis and psychosis: a critical overview of the relationship," Current Psychiatry Reports, vol. 18, no. 2, pp. 1-11, 2016.

[18] C. Andrade, "Cannabis and neuropsychiatry, 2: the longitudinal risk of psychosis as an adverse outcome," Journal of Clinical Psychiatry, vol. 77, no. 6, pp. e739-e742, 2016.

[19] L. V. Panlilio, S. Ferré, S. Yasar, E. B. Thorndike, C. W. Schindler, and S. R. Goldberg, "Combined effects of THC and caffeine on working memory in rats," British Journal of Pharmacology, vol. 165, no. 8, pp. 2529-2538, 2012.

[20] A. M. Spaeth, N. Goel, and D. F. Dinges, "Cumulative neurobehavioral and physiological effects of chronic caffeine intake: individual differences and implications for the use of caffeinated energy products," Nutrition Reviews, vol. 72, no. 1, pp. 34-47, 2014.

[21] E. T. Kahn-Greene, D. B. Killgore, G. H. Kamimori, T. J. Balkin, and W. D. S. Killgore, "The effects of sleep deprivation on symptoms of psychopathology in healthy adults," Sleep Medicine, vol. 8, no. 3, pp. 215-221, 2007.

[22] D. Freeman, K. Pugh, N. Vorontsova, and L. Southgate, "Insomnia and paranoia," Schizophrenia Research, vol. 108, no. 1-3, pp. 280-284, 2009.

[23] N. Petrovsky, U. Ettinger, A. Hill et al., "Sleep deprivation disrupts prepulse inhibition and induces psychosis-like symptoms in healthy humans," The Journal of Neuroscience, vol. 34, no. 27, pp. 9134-9140, 2014.

[24] W. Zareba and D. A. Lin, "Antipsychotic drugs and QT interval prolongation," Psychiatric Quarterly, vol. 74, no. 3, pp. 291-306, 2003.

[25] C. Stöllberger, J. O. Huber, and J. Finsterer, "Antipsychotic drugs and QT prolongation," International Clinical Psychopharmacology, vol. 20, no. 5, pp. 243-251, 2005.

[26] N. Nagajothi, A. Khraisat, J.-L. E. Velazquez-Cecena et al., "Energy drink-related supraventricular tachycardia," American Journal of Medicine, vol. 121, no. 4, pp. e3-e4, 2008.

[27] D. Rottlaender, L. J. Motloch, S. Reda, R. Larbig, and U. C. Hoppe, "Cardiac arrest due to long QT syndrome associated with excessive consumption of energy drinks," International Journal of Cardiology, vol. 158, no. 3, pp. e51-e52, 2012.

[28] D. Menci, F. M. Righini, M. Cameli et al., "Acute effects of an energy drink on myocardial function assessed by conventional echo-Doppler analysis and by speckle tracking echocardiography on young healthy subjects," Journal of Amino Acids, vol. 2013, Article ID 646703, 7 pages, 2013.

[29] J. P. Higgins, S. Yarlagadda, and B. Yang, "Cardiovascular complications of energy drinks," Beverages, vol. 1, no. 2, pp. 104126, 2015.

[30] S. Hajsadeghi, F. Mohammadpour, M. J. Manteghi et al., "Effects of energy drinks on blood pressure, heart rate, and electrocardiographic parameters: an experimental study on healthy young adults," The Anatolian Journal of Cardiology, vol. 16, no. 2, pp. 94-99, 2015.

[31] J. P. Higgins, "Endothelial function acutely worse after drinking energy beverage," International Journal of Cardiology, vol. 168, no. 2, pp. e47-e49, 2013.

[32] J. P. Higgins and K. M. Babu, "Caffeine reduces myocardial blood flow during exercise," American Journal of Medicine, vol. 126, no. 8, pp. 730.e1-730.e8, 2013.

[33] J. P. Higgins and B. Ortiz, "Energy drink ingredients and their effect on endothelial function: a review," International Journal of Clinical Cardiology, vol. 1, pp. 1-6, 2014.
[34] L. Cruzado, M. Sánchez-Fernández, C. Cortez-Vergara, and G. Rojas-Rojas, "Mania induced by high content caffeinated energy drinks," Actas Espanolas de Psiquiatria, vol. 42, no. 5, pp. 259262, 2014.

[35] A. Szpak and D. Allen, "A case of acute suicidality following excessive caffeine intake," Journal of Psychopharmacology, vol. 26, no. 11, pp. 1502-1504, 2012.

[36] É. Rizkallah, M. Bélanger, K. Stavro et al., "Could the use of energy drinks induce manic or depressive relapse among abstinent substance use disorder patients with comorbid bipolar spectrum disorder?" Bipolar Disorders, vol. 13, no. 5-6, pp. 578580, 2011

[37] J. M. Cerimele, A. P. Stern, and D. Jutras-Aswad, "Psychosis following excessive ingestion of energy drinks in a patient with schizophrenia," American Journal of Psychiatry, vol. 167, no. 3, p. 353,2010

[38] T. Berigan, "An anxiety disorder secondary to energy drinks: a case report," Psychiatry (Edgmont), vol. 2, no. 10, p. 10, 2005.

[39] J. Chelben, A. Piccone-Sapir, I. Ianco, N. Shoenfeld, M. Kotler, and R. D. Strous, "Effects of amino acid energy drinks leading to hospitalization in individuals with mental illness," General Hospital Psychiatry, vol. 30, no. 2, pp. 187-189, 2008.

[40] R. Machado-Vieira, C. I. Viale, and F. Kapczinski, "Mania associated with an energy drink: the possible role of caffeine, taurine, and inositol," Canadian Journal of Psychiatry, vol. 46, no. 5, pp. 454-455, 2001.

[41] D. B. Menkes, “Transient psychotic relapse temporally related to ingestion of an "energy drink"," The Medical Journal of Australia, vol. 194, no. 4, p. 206, 2011.

[42] V. Sharma, "Red bull and mania," German Journal of Psychiatry, vol. 13, no. 4, pp. 178-180, 2010. 


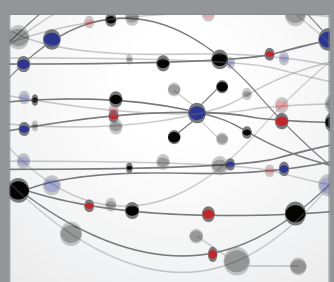

The Scientific World Journal
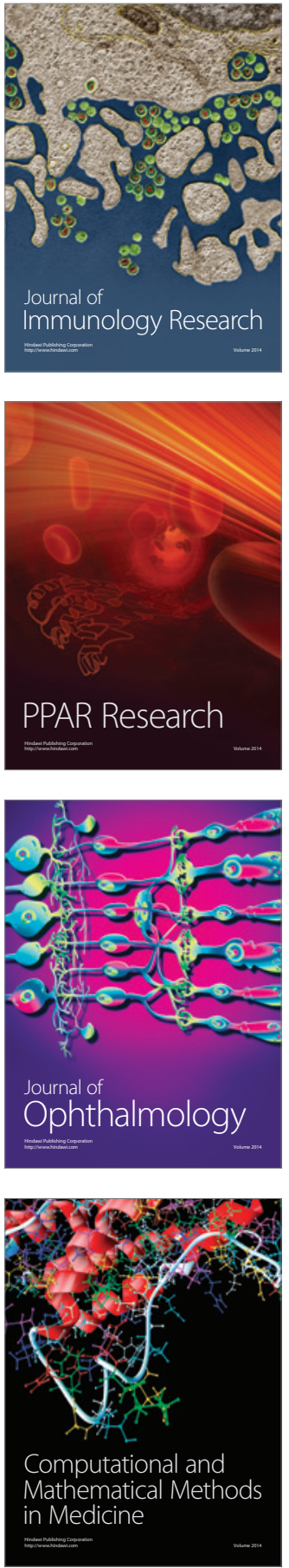

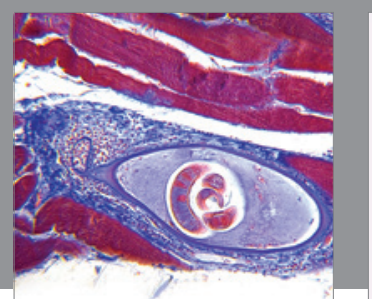

Gastroenterology Research and Practice
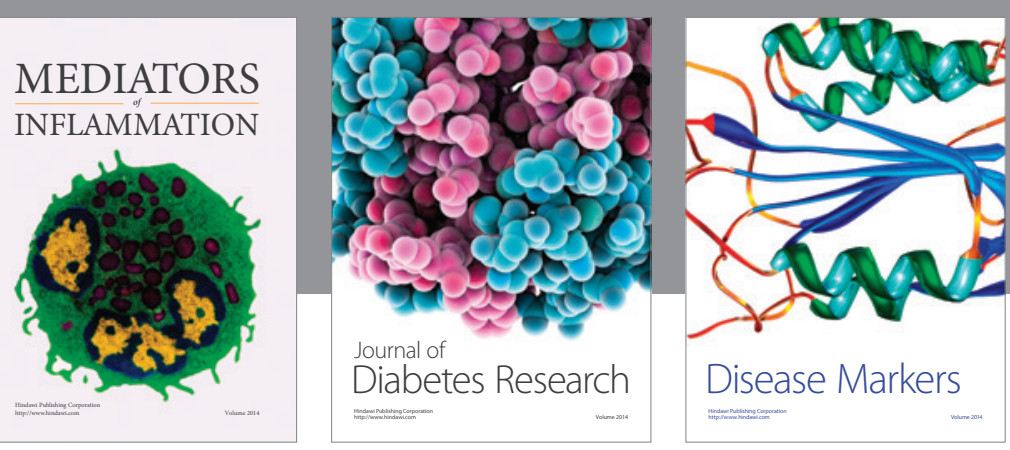

Disease Markers

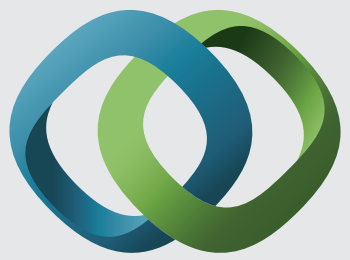

\section{Hindawi}

Submit your manuscripts at

https://www.hindawi.com
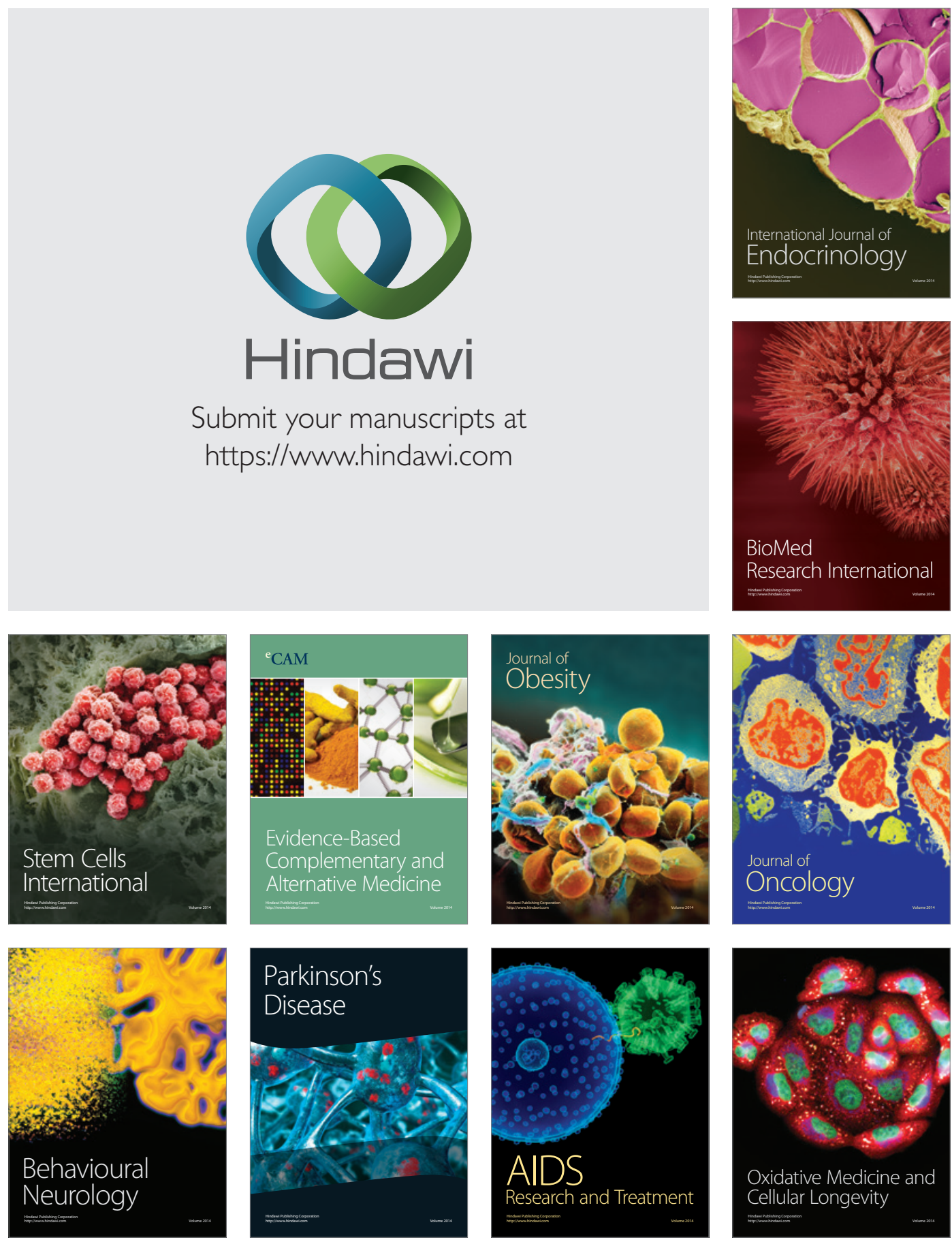